\title{
The Relationship between Quality of Life and Cognitive Functions, Anxiety and Depression among Hospitalized Elderly Patients
}

\author{
Özge Saraçl1 ${ }^{1}$, Ayşe Semra Demir Akca ${ }^{2}$, Nuray Atasoy ${ }^{1}$, Özde Önder ${ }^{3}$, Ömer Şenormanc1 ${ }^{1}$, İsmet Kaygisız ${ }^{1}$, Levent \\ Atik $^{1}$ \\ Departments of ${ }^{1}$ Psychiatry and ${ }^{2}$ Family Medicine, Bulent Ecevit University Faculty of Medicine, ${ }^{3}$ Public Health Center, Zonguldak, Turkey
}

\begin{abstract}
Objective: Older people seek not only a longer life, but also a better quality of life (QOL). Our aim was to find out the relationship between QOL and socio-demographic factors, social activities, cognitive status, depression and anxiety symptoms among medically ill and hospitalized elderly people in Turkey.

Methods: Two hundred forty three patients age 65 years or older were examined. The Socio-demographic Data Survey, the Mini Mental State Examination (MMSE), the Geriatric Depression Scale-short form (GDS-15), the Beck Anxiety Inventory (BAI) and the World Health Organization Quality of Life Instrument-Older Adults Module (WHOQOL-OLD) were applied to participants. The independent samples $t$-test and analysis of variance (ANOVA) were used to analyze quantitative data. Pearson's correlation and linear regression analysis were performed.

Results: The total score for QOL was significantly higher for those who saw their family members and relatives frequently rather than rarely $(p=0.002)$, who were always busy with social activities rather than rarely or never $(p<0.001)$, who had more years of education $(p=0.003)$, and who were frequently exercising $(p=0.023)$. According to linear regression analysis, the WHOQOL-OLD total score increased by 0.295 and -0.936 units, while MMSE and GDS-15 scale scores increased one unit respectively ( $\beta=0.295, \mathrm{t}=1.979, \quad p=0.04 ; \beta=-0.936, \mathrm{t}=-4.881, \quad p<0.001$ ).

Conclusion: Cognitive disabilities, depression, and other psychiatric problems along with medical disease negatively affect the QOL of elderly patients. While performing medical assessment regarding elders, detecting and treating cognitive disabilities and depression is very valuable in improving the QOL of elderly patients.
\end{abstract}

KEY WORDS: Quality of Life; Aged; Depression; Cognition.

\section{INTRODUCTION}

The world population has rapidly grown older in the last 50 years with the lengthening of lifespan and a decrease in birth rates. According to the census results in Turkey, in 2000 , and 2013 the population of adults who were 65 years and older were $5 \%$, and $7 \%$, respectively. ${ }^{1)}$

Older people seek not only a longer duration of life but also a better quality of life (QOL). Physical or mental health-related problems have been associated with one's QOL worldwide. ${ }^{2)}$ Therefore, it is crucial to understand the factors influencing health to improve QOL for the elderly in Turkey.

\footnotetext{
Received: January 12, 2015 / Revised: February 11, 2015

Accepted: March 6, 2015

Address for correspondence: Özge Saraçlı, MD

Department of Psychiatry, Bulent Ecevit University Faculty of

Medicine, Esenköy-Kozlu, 67600 Zonguldak, Turkey

Tel: +90-372-2612379, Fax: +90-372-2610155

E-mail: osimsekyilmaz@yahoo.com
}

The health status of the elderly should be assessed comprehensively, not only with regard to their physical condition, but also emotional condition, social activity, and QOL. ${ }^{3)}$ Depression, anxiety, and cognitive impairments are the health-related conditions that have been reported to be important for QOL. The impact of cognitive problems on QOL has been assessed in various studies. ${ }^{4-6)}$

The studies of hospitalized elderly with medical disorders have focused on the prevalence of depression and associated factors. ${ }^{7)}$ Medical information about chronic diseases, the number of medications prescribed, disease-specific physical symptoms, use of health and social services, etc. may express different aspects of health. These factors have been reported to be associated with the QOL or domains of the QOL in elderly patients with medical problems. ${ }^{8)}$ Even though the research on how health status is associated with the QOL is increasing, few studies have investigated the QOL from samples of the elderly in general hospitals.

(c) This is an Open-Access article distributed under the terms of the Creative Commons Attribution Non-Commercial License (http://creativecommons.org/licenses/by-nc/4.0) which permits unrestricted non-commercial use, distribution, and reproduction in any medium, provided the original work is properly cited. 
As our population grows older, the issue of improving the QOL of the elderly will become increasingly important. We aimed to find answers to the following queries: (1) whether socio-demographic factors, social activities, and leisure time activities affect QOL, (2) whether patients' cognitive status affects QOL, and (3) whether depression and anxiety symptoms affect QOL among medically ill and hospitalized elderly people in Turkey. This study was part of our other study entitled "Relationship of cognitive functions to clinical variables of daily activities, depression, and anxiety among hospitalized elderly. ${ }^{9)}$

\section{METHODS}

This study, conducted in a cross-sectional and descriptive design, was pre-approved by the Clinical Research Ethics Board at Bülent Ecevit University (2012-74-02/05).

The criteria for inclusion in the study were being the age of 65 years or older and having been hospitalized. The exclusion criteria were the inability to comprehend and/or incapability of cooperation in the completion of surveys, hearing or sight problems, and refusal to participate in the study. Between June 1st and August 31st, 2012 at the Bülent Ecevit University Research and Application Hospital, 243 (63.1\%) of 385 resident patients whose age was 65 years or older, excluding those in intensive care, met the predetermined study inclusion criteria.

\section{Application}

The study's data was collected between the first 24 to 48 hours of hospitalization to rule out additional problems associated with hospitalization by the researchers through personal interviews with the patients after obtaining written consent. During the application of the Socio-demographic Data Survey in addition to the elderly patient, any relatives accompanying the patient were also used as source of information. After the application of the Mini Mental State Examination (MMSE), the patients were asked to fill out the Geriatric Depression Scale-short form (GDS-15), the Beck Anxiety Inventory (BAI) and the World Health Organization Quality of Life InstrumentOlder Adults Module (WHOQOL-OLD).

\section{Measurement Tools}

\section{Socio-demographic Data Form}

This survey form included these items: age, gender, education level, marital status, monthly income level (low
$<1,000$ Turkish Liras [TL], high $>1,001$ TL), cohabitation status, leisure time activities, physical disease and psychiatric disorder history, and psychiatric treatment history in the last six months. The frequency of meeting family members was measured by the three point Likert scale by self-assessment. Information about chronic diseases was collected by scanning patient hospital records and by interviews with patients and relatives. Hypertension, diabetes mellitus, coronary artery disease, chronic heart failure, chronic obstructive pulmonary disease, chronic renal failure, sequel of cerebrovascular disease, rheumatoid arthritis, osteoporosis, and cataract was defined as a chronic disease.

\section{Mini Mental State Examination (MMSE)}

This is a frequently used and easily applicable test developed by Folstein et al. ${ }^{10)}$ to determine a patient's degree of cognitive disorder. The validity and reliability of the MMSE have been assessed according to the education levels of citizens and the threshold value was determined to be $23 / 24$ points in screening for potential dementia. ${ }^{11)}$

\section{Geriatric Depression Scale-short form (GDS-15)}

This test was developed for screening for depression in elderly patients. ${ }^{12)}$ Developed for ease of use, the 15-item short form is applicable rapidly. The GDS short form has been validated and its reliability has been established in Turkey. ${ }^{13)}$ In this scale, a score of 6 or higher may be indicative of depression and must be evaluated jointly with patient's clinical data.

\section{Beck Anxiety Inventory (BAI)}

Developed by Beck et al., ${ }^{14)}$ this scale is a Likert-type self-assessment measure consisting of 21 items. Turkish validity and reliability studies have been done by Ulusoy et al. ${ }^{15)}$

\section{World Health Organization Quality of Life Instrument-Older Adults Module (WHOQOL-OLD)}

The WHOQOL-OLD is a QOL module designed for the older population. ${ }^{16)}$ This module consists of 24 Likerttype questions and six subfields. These domains are categorized as sensory abilities, autonomy, past, present and future activities, social participation, death and dying, and intimacy. Validity and reliability of the WHOQOL-OLD form was shown by Eser et al. ${ }^{17)}$ in Turkey. QOL increased with the score obtained from the relevant domains. 


\section{Statistical Analysis}

In the analysis of the present study, the SPSS software package version 16.0 (SPSS Inc., Chicago, IL, USA) was utilized. Numeric variables were given as means \pm standard deviations and categorical variables were shown as numbers and percentage values. Categorical data were analyzed using the chi-square test. The independent samples $t$-test and analysis of variance (ANOVA) were used to analyze quantitative data. Pearson's correlation was used to measure the relationship between measurement scales. Linear regression analysis was performed to test the effect of education years, MMSE scores, and GDS-15 scale scores on WHOQOL-OLD total scores. Elimination was performed by the backward stepwise method after variables were placed in analysis. Statistical significance was set as $p<0.05$ and $p<0.001$.

Table 1. The average scores of the scales applied elderly sample

\begin{tabular}{lc}
\hline \multicolumn{1}{c}{ Scale } & Score \\
\hline MMSE & $21.4 \pm 5.6$ \\
BAI & $16.91 \pm 11.78$ \\
GDS-15 & $6.02 \pm 4.34$ \\
WHOQOL-OLD & \\
Sensory abilities & $49.17 \pm 14.27$ \\
Autonomy & $43.67 \pm 20.97$ \\
Past, present and future activities & $46.86 \pm 14.73$ \\
Social participation & $57.35 \pm 21.10$ \\
Death and dying & $51.38 \pm 22.34$ \\
Intimacy & $59.79 \pm 22.53$ \\
Total & $51.37 \pm 12.83$ \\
\hline Values are presented as mean \pm standard deviation. \\
MMSE, Mini Mental State Examination; BAl, Beck Anxiety Inven- \\
tory; GDS-15, Geriatric Depression Scale-short form; WHOQOL-OLD, \\
World Health Organization Quality of Life Instrument-Older Adults \\
Module.
\end{tabular}

\section{RESULTS}

Participants of the study consisted of 106 female (43.6\%) and 137 male (56.4\%) patients. The mean age of the sample was $73.4 \pm 6.2$, the mean education year was $5.4 \pm 1.6$. Total of $64.6 \%$ of the patients were married, and $57.2 \%$ of the sample were living in rural areas. Of the participants, $87.8 \%$ were low monthly income levels and $12.2 \%$ were high. Of the elderly, $23.0 \%$ were regularly exercising.

Twenty five $(10.3 \%)$ of the patients had previous psychiatric admission and $22(9.1 \%)$ had treatment history. Eighty six percent of the elderly $(87.4 \%$ of women and $88.1 \%$ of men, $p=0.505$ ) were diagnosed with chronic diseases. Of the patients, $62.1 \%$ were hospitalized in internal medicine section and $37.9 \%$ in the surgical section. The clinical scale scores were presented in Table 1.

QOL scores were significantly higher for those who saw their family members and relatives frequently rather than rarely $(\mathrm{n}=172$ [70.8\%], $\mathrm{n}=53$ [21.8\%], respectively; $p=0.002$ ); who were always busy with leisure time activities rather than rarely or never $(n=58$ [23.9\%], $n=86$ [35.4\%], $\mathrm{n}=64$ [26.3\%], respectively; $p<0.001$ ). Table 2 shows the relationships between the socio-demographic variables, clinical scale scores, and the WHOQOL-OLD scores. There was positive correlation between BAI and "autonomy," and negative correlation between BAI and "social participation," "death and dying" and, "intimacy" subfields of WHOQOL-OLD. There was not correlation between BAI and total score of WHOQOL-OLD (Table 2). The comparison of the elderly socio-demographic, clinical features, and leisure activities with the WHOQOL-OLD

Table 2. Correlations to elderly socio-demographic features and scales with WHOQOL-OLD subfields

\begin{tabular}{|c|c|c|c|c|c|c|c|c|}
\hline \multirow{2}{*}{\multicolumn{2}{|c|}{$\begin{array}{c}\text { Socio-demographic } \\
\text { features }\end{array}$}} & \multicolumn{7}{|c|}{ WHOQOL-OLD } \\
\hline & & \multirow{2}{*}{$\begin{array}{c}\begin{array}{c}\text { Sensory } \\
\text { abilities }\end{array} \\
0.017\end{array}$} & \multirow{2}{*}{$\begin{array}{c}\text { Autonomy } \\
-0.001\end{array}$} & \multirow{2}{*}{$\begin{array}{c}\text { Past, present } \\
\text { and future } \\
0.057\end{array}$} & \multirow{2}{*}{$\begin{array}{c}\begin{array}{c}\text { Social } \\
\text { participation }\end{array} \\
0.029\end{array}$} & \multirow{2}{*}{$\begin{array}{c}\begin{array}{c}\text { Death and } \\
\text { dying }\end{array} \\
-0.021\end{array}$} & \multirow{2}{*}{$\frac{\text { Intimacy }}{0.058}$} & \multirow{2}{*}{$\begin{array}{c}\text { Total } \\
0.033\end{array}$} \\
\hline Age & $\gamma$ & & & & & & & \\
\hline & $p$ value & 0.792 & 0.982 & 0.380 & 0.654 & 0.750 & 0.364 & 0.613 \\
\hline Education years & $\gamma$ & 0.122 & 0.014 & $0.129^{*}$ & $0.204^{*}$ & $0.207^{*}$ & 0.073 & $0.188^{*}$ \\
\hline & $p$ value & 0.057 & 0.829 & 0.045 & 0.001 & 0.001 & 0.259 & 0.003 \\
\hline \multicolumn{9}{|l|}{ Scales } \\
\hline \multirow[t]{2}{*}{ MMSE } & $\gamma$ & 0.021 & -0.049 & 0.043 & $0.305^{*}$ & $0.276^{*}$ & $0.185^{\star}$ & $0.217^{*}$ \\
\hline & $p$ value & 0.747 & 0.449 & 0.503 & $<0.001$ & $<0.001$ & 0.004 & 0.001 \\
\hline \multirow[t]{2}{*}{ GDS-15 } & $\gamma$ & 0.009 & $0.274^{*}$ & -0.115 & $-0.539^{*}$ & $-0.501^{*}$ & $-0.390^{\star}$ & $-0.356^{*}$ \\
\hline & $p$ value & 0.898 & $<0.001$ & 0.081 & $<0.001$ & $<0.001$ & $<0.001$ & $<0.001$ \\
\hline \multirow[t]{2}{*}{ BAI } & $\gamma$ & 0.096 & $0.320^{*}$ & 0.066 & $-0.227^{\star}$ & $-0.292^{*}$ & $-0.166^{\star}$ & -0.078 \\
\hline & $p$ value & 0.143 & $<0.001$ & 0.318 & $<0.001$ & $<0.001$ & 0.012 & 0.237 \\
\hline
\end{tabular}

MMSE, Mini Mental State Examination; GDS-15, Geriatric Depression Scale-short form; BAI, Beck Anxiety Inventory; WHOQOL-OLD, World Health Organization Quality of Life Instrument-Older Adults Module. Pearson's correlation test was performed.

${ }^{*} p<0.05$. 
Table 3. Comparison to elderly socio-demographic and clinical features with WHOQOL-OLD subfields

\begin{tabular}{|c|c|c|c|c|c|c|c|}
\hline \multirow{2}{*}{$\begin{array}{l}\text { Socio-demographic } \\
\text { features }\end{array}$} & \multicolumn{7}{|c|}{ WHOQOL-OLD } \\
\hline & $\begin{array}{l}\text { Sensory } \\
\text { abilities }\end{array}$ & Autonomy & $\begin{array}{l}\text { Past, presentand } \\
\text { future }\end{array}$ & $\begin{array}{c}\text { Social } \\
\text { participation }\end{array}$ & $\begin{array}{l}\text { Death and } \\
\text { dying }\end{array}$ & Intimacy & Total \\
\hline \multicolumn{8}{|l|}{ Gender } \\
\hline Male & $50.86 \pm 1.2$ & $41.14 \pm 1.7$ & $46.21 \pm 1.2$ & $58.75 \pm 1.8$ & $51.27 \pm 1.8$ & $58.43 \pm 1.8$ & $51.11 \pm 1.0$ \\
\hline Female & $46.99 \pm 1.3$ & $46.93 \pm 2.0$ & $47.70 \pm 1.4$ & $55.54 \pm 1.9$ & $51.53 \pm 2.2$ & $61.55 \pm 2.2$ & $51.70 \pm 1.2$ \\
\hline$p$ value & $0.034^{*}$ & $0.033^{*}$ & 0.436 & 0.239 & 0.930 & 0.286 & 0.722 \\
\hline \multicolumn{8}{|l|}{ Monthly income level } \\
\hline Low & $48.86 \pm 13.9$ & $44.20 \pm 21.0$ & $46.90 \pm 14.6$ & $56.56 \pm 20.9$ & $50.36 \pm 22.3$ & $59.23 \pm 22.5$ & $51.02 \pm 12.8$ \\
\hline High & $52.17 \pm 16.8$ & $38.58 \pm 19.6$ & $46.46 \pm 15.6$ & $64.9 \pm 21.2$ & $61.14 \pm 20.11$ & $65.21 \pm 21.63$ & $54.75 \pm 12.6$ \\
\hline$p$ value & 0.655 & 0.194 & 0.982 & $0.046^{*}$ & $0.019^{*}$ & 0.218 & 0.130 \\
\hline \multicolumn{8}{|l|}{ Marital state } \\
\hline Widowed-divorced & $48.90 \pm 1.5$ & $45.93 \pm 2.4$ & $47.38 \pm 1.6$ & $57.41 \pm 2.2$ & $50.87 \pm 2.4$ & $60.31 \pm 2.5$ & $51.80 \pm 1.4$ \\
\hline Married & $49.32 \pm 1.1$ & $42.43 \pm 1.5$ & $46.57 \pm 1.1$ & $57.32 \pm 1.7$ & $51.67 \pm 1.7$ & $59.51 \pm 1.7$ & $51.14 \pm 1.0$ \\
\hline$p$ value & 0.830 & 0.215 & 0.684 & 0.975 & 0.790 & 0.791 & 0.701 \\
\hline \multicolumn{8}{|l|}{ Location } \\
\hline Rural & $49.91 \pm 1.2$ & $45.27 \pm 1.8$ & $46.71 \pm 1.3$ & $55.66 \pm 1.6$ & $49.10 \pm 1.8$ & $59.12 \pm 1.8$ & $50.96 \pm 1.0$ \\
\hline Urban & $48.19 \pm 1.3$ & $41.52 \pm 1.9$ & $47.05 \pm 1.3$ & $59.61 \pm 2.2$ & $54.44 \pm 2.2$ & $60.69 \pm 2.2$ & $51.92 \pm 1.2$ \\
\hline $\mathrm{p}$ value & 0.356 & 0.168 & 0.860 & 0.149 & 0.065 & 0.592 & 0.567 \\
\hline \multicolumn{8}{|l|}{ Chronic diseases } \\
\hline Absent & $48.06 \pm 1.8$ & $44.18 \pm 3.1$ & $46.55 \pm 2.3$ & $55.38 \pm 4.0$ & $49.13 \pm 4.3$ & $56.89 \pm 5.2$ & $50.03 \pm 2.5$ \\
\hline Present & $49.73 \pm 1.0$ & $44.04 \pm 1.4$ & $47.12 \pm 1.0$ & $57.56 \pm 1.4$ & $51.58 \pm 1.5$ & $60.19 \pm 1.5$ & $51.70 \pm 0.8$ \\
\hline$p$ value & 0.550 & 0.975 & 0.843 & 0.605 & 0.582 & 0.464 & 0.514 \\
\hline \multicolumn{8}{|l|}{ Psychiatric treatment } \\
\hline Absent & $49.85 \pm 0.9$ & $44.21 \pm 1.4$ & $46.83 \pm 1.0$ & $58.02 \pm 1.4$ & $52.20 \pm 1.5$ & $60.23 \pm 1.5$ & $51.89 \pm 0.8$ \\
\hline Present & $43.18 \pm 3.4$ & $40.62 \pm 4.7$ & $46.87 \pm 3.3$ & $50.85 \pm 4.5$ & $44.03 \pm 4.2$ & $55.68 \pm 3.7$ & $46.87 \pm 2.7$ \\
\hline$p$ value & $0.037^{\star}$ & 0.448 & 0.990 & 0.130 & 0.103 & 0.370 & 0.083 \\
\hline
\end{tabular}

Values are presented as mean \pm standard deviation.

WHOQOL-OLD, World Health Organization Quality of Life Instrument-Older Adults Module.

Independent samples t-test was performed.

${ }^{*} p<0.05$.

Table 4. Comparison to leisure activities of elderly with WHOQOL-OLD subfields

\begin{tabular}{|c|c|c|c|c|c|c|c|}
\hline \multirow{2}{*}{ Leisure activities } & \multicolumn{7}{|c|}{ WHOQOL-OLD } \\
\hline & $\begin{array}{l}\text { Sensory } \\
\text { abilities }\end{array}$ & Autonomy & $\begin{array}{l}\text { Past, present } \\
\text { and future }\end{array}$ & $\begin{array}{c}\text { Social } \\
\text { participation }\end{array}$ & $\begin{array}{l}\text { Death and } \\
\text { dying }\end{array}$ & Intimacy & Total \\
\hline \multicolumn{8}{|l|}{ Exercise } \\
\hline Absent & $48.72 \pm 1.0$ & $44.71 \pm 1.5$ & $46.12 \pm 1.0$ & $55.01 \pm 1.4$ & $49.19 \pm 1.5$ & $58.32 \pm 1.6$ & $50.35 \pm 0.9$ \\
\hline Present & $50.66 \pm 2.1$ & $40.17 \pm 2.6$ & $49.33 \pm 1.8$ & $65.17 \pm 3.0$ & $58.70 \pm 3.0$ & $64.73 \pm 3.1$ & $54.79 \pm 1.7$ \\
\hline$p$ value & 0.373 & 0.156 & 0.153 & $0.001^{*}$ & $0.005^{\star}$ & 0.062 & $0.023^{*}$ \\
\hline \multicolumn{8}{|l|}{ Chat } \\
\hline Absent & $49.00 \pm 1.3$ & $44.29 \pm 1.9$ & $43.99 \pm 1.2$ & $52.03 \pm 1.8$ & $45.83 \pm 1.9$ & $53.96 \pm 1.8$ & $48.18 \pm 1.1$ \\
\hline Present & $49.24 \pm 1.3$ & $42.52 \pm 1.8$ & $49.35 \pm 1.4$ & $63.20 \pm 1.9$ & $57.35 \pm 2.0$ & $65.24 \pm 2.2$ & $54.48 \pm 1.1$ \\
\hline$p$ value & 0.903 & 0.518 & $0.005^{*}$ & $<0.001^{*}$ & $<0.001^{*}$ & $<0.001^{*}$ & $<0.001^{*}$ \\
\hline \multicolumn{8}{|l|}{ Friendship } \\
\hline Absent & $47.19 \pm 2.0$ & $47.95 \pm 3.0$ & $48.08 \pm 2.2$ & $51.78 \pm 3.1$ & $44.77 \pm 3.2$ & $54.08 \pm 3.0$ & $48.97 \pm 1.8$ \\
\hline Present & $49.67 \pm 1.0$ & $42.59 \pm 1.4$ & $46.55 \pm 1.0$ & $58.76 \pm 1.4$ & $53.06 \pm 1.5$ & $61.24 \pm 1.6$ & $51.98 \pm 0.9$ \\
\hline$p$ value & 0.277 & 0.109 & 0.516 & $0.038^{*}$ & $0.020^{*}$ & $0.047^{\star}$ & 0.144 \\
\hline \multicolumn{8}{|l|}{ Roam } \\
\hline Absent & $49.36 \pm 1.1$ & $44.13 \pm 1.7$ & $45.31 \pm 1.1$ & $52.74 \pm 1.6$ & $46.79 \pm 1.7$ & $56.41 \pm 1.7$ & $49.12 \pm 0.9$ \\
\hline Present & $48.67 \pm 1.6$ & $42.35 \pm 2.1$ & $48.45 \pm 1.6$ & $64.85 \pm 2.2$ & $58.67 \pm 2.5$ & $63.89 \pm 2.5$ & $54.48 \pm 1.4$ \\
\hline$p$ value & 0.726 & 0.532 & 0.117 & $<0.001^{*}$ & $<0.001^{*}$ & $0.015^{\star}$ & $0.002^{*}$ \\
\hline
\end{tabular}

Values are presented as mean \pm standard deviation.

WHOQOL-OLD, World Health Organization Quality of Life Instrument-Older Adults Module.

Independent samples $t$-test was performed.

${ }^{*} p<0.05$.

subfields were shown in the Tables 3 and 4 . The sensory abilities subfield of WHOQOL-OLD in males and the autonomy subfield of WHOQOL-OLD in females were sig- nificantly higher, but there were no gender differences found in the other WHOQOL-OLD subfields. The elders who continue daily activities, such as exercising, roaming, 
and conversing with others had significantly higher scores in the total, "social participation," "death and dying," and "intimacy" subfields of WHOQOL-OLD than elders who did not.

Linear regression analysis was performed to test the effect of education years, MMSE scores, and GDS- 15 scale scores on WHOQOL-OLD total scores. Elimination was performed by the backward stepwise method after the variables were placed in the analysis. In the second step education year was eliminated. The regression model was statistically significant $(\mathrm{F}=18.732, p<0.001)$. WHOQOLOLD total scores increases by 0.295 and -0.936 units, while MMSE and GDS- 15 scale scores increases one unit respectively $(\beta=0.295, \mathrm{t}=1.979, p=0.04 ; \beta=-0.936, \mathrm{t}=$ $-4.881, p<0.001)$. The MMSE and GDS- 15 scales explained 0.134 of the variance in the WHOQOL-OLD total score $\left(\mathrm{R}^{2}=0.134\right)$.

\section{DISCUSSION}

The aim of this study was to evaluate effects of socio-demographic and clinical features on the QOL. Many studies reported negative correlations between age and QOL ${ }^{18-21)}$ while one study reported no correlations. ${ }^{22)}$ It is noted in the literature that QOL scores decrease with aging and QOL is better below the age of 70 years. ${ }^{18)}$ In our study there was not a correlation between age and QOL. Psycho-social factors and mental health problems were more apparent. So age and gender may not have a significant effect on QOL.

In Turkey, QOL studies performed with elders suggested that subfield scores of QOL was higher for males. ${ }^{17,18,23,24)}$ In relevant literature, it was reported that this can be related to decreased physical activity and troubles in daily living activities caused by a higher incidence of chronic diseases that were more prevalent in females than males. ${ }^{18,23)}$ Also in another study, this was related to the different social roles of males and females, and physiological and psychological factors. ${ }^{24)}$ It is important to examine the effects of gender on QOL by further studies. In contrast with several articles, we found the sensory abilities subfield of males and the autonomy subfield of females was significantly higher, but there were no gender differences in the other WHOQOL-OLD subfields. We suggested that the autonomy subfield scores of female were higher because the ability to live alone among females was higher than males in our country. In the study of Özyurt et al. ${ }^{18)}$ males had higher subfield scores except in sensory abilities, and death and dying. We did not find a difference in QOL scores between males and females. We think that this may be related to the high incidence of chronic diseases in both males and females.

In the literature, there is a positive correlation between education level and QOL. ${ }^{1,18,19,25)}$ In our study, we found a significant positive correlation between education level and the QOL Total score, subfield scores of 'death and dying', 'past present and future activities', and 'social participation'. A higher education level may cause more social relationships and intellectual capacity, so that it affects the QOL positively.

The most important factor that affects the QOL of elders is chronic diseases. In a study of elders with renal failure, depression, and cognitive impairment were frequent and they suggested that the examination of depression, cognitive functions, and QOL should be done. ${ }^{26)}$ In contrast with other studies from Turkey, we did not find a relationship between the presence of chronic diseases and QOL. ${ }^{18,27)}$ Although $86 \%$ of elders had chronic diseases in our study, there was not a significant difference between the means of the total QOL score and the subfield scores for individuals with or without chronic diseases. These individuals may be considered healthy, even if they have chronic, degenerative, but controlled diseases. All of the participants were hospitalized but as they were undergoing treatment and maintained an expectancy of wellness this could explain the difference in results.

Similar to the literature, the history of psychiatric disorder, levels of depression and anxiety was negatively correlated with QOL. ${ }^{1,28}$ In our study, we found that there was a negative correlation between GDS-15, BAI and 'social participation', 'death and dying', and 'intimacy' subfield scores. Although depression was the most common psychiatric disorder in elders and depression and anxiety levels of the individuals were high, only $9.3 \%$ of them had psychiatric treatment history. The underdiagnosis and undertreatment of psychiatric disorders affect the functionality of elders and QOL dramatically. In literature, it was reported that mental disabilities affects QOL more than physical diseases. ${ }^{22)}$ The detection and treatment of depression and anxiety of elders who are hospitalized is very important to protect QOL. ${ }^{9)}$

Cognitive dysfunction is a common problem among elderly people. Population-based studies report that most community dwelling elderly people suffer from cognitive problems. Advancing age is associated with an increase in health complications that can lead to disability. The elderly may suffer from illness, disabilities, and functional impairments, that are related to cognitive problems, which 
make them dependent on others for care and help in their daily life. ${ }^{6,9)}$ In our study there was a positive correlation between MMSE and the QOL total score and "social participation", "death and dying" and "intimacy" subfields. We found that MMSE and GDS-15 scale scores were the most powerful negative predictors of QOL after linear regression analysis. As we mentioned in our previous studies, screening of depression and cognitive functions in elders is very important. ${ }^{9}$

Engaging in leisure activity has the potential to improve QOL. A recent longitudinal study also reported the preventive role of leisure time and physical activity in depression. ${ }^{29)}$ The top five most popular leisure activities among the elderly are watching television, taking a walk, reading newspapers, visiting relatives or chatting and traveling. ${ }^{30)}$ In our study, elders who continue daily activities such as exercising, roaming and conversing with others had significantly higher total and subfield scores from WHOQOL-OLD.

One of the important indicators of QOL is social functionality. ${ }^{6,7)}$ According to Xavier et al., ${ }^{31)}$ having good health, good family relationships, financial security, friends and work ability are determinants of good QOL. In our study, the QOL was better in elders who continue their relationships with relatives and friends. Thus it is important to encourage social functionality in the elderly.

There are some limitations in our study. We could not evaluate all possible factors, such as nutritional pattern, perception of illness, or personal features. And we did not perform any clinical assessment information beside anxiety and depression scales. But, the GDS and MMSE were chosen because they have been extensively studied for diagnostic purposes. Longitudinal studies are required to address this issue.

In conclusion, according to our findings, although presence of chronic disease, age, marital status, and gender do not affect QOL; cognitive disabilities, depression, and other psychiatric problems with medical diseases negatively affect QOL of elderly patients. These findings show that screening for mental and cognitive disorders is very important for the well-being of elders. While performing medical assessment regarding elders, detecting and treating disabilities of cognitive status and depression is very valuable to improve the QOL of elder patients.

\section{REFERENCES}

1. Akyol Y, Durmuş D, Doğan C, Bek Y, Cantürk F. Quality of life and level of depressive symptoms in the geriatric population. Turk J Rheumatol 2010;25:165-173.

2. Chiao CY, Lee SH, Liao WC, Yen CH, Lin YJ, Li CR, et al. Social participation and life expectancy the case of older adults in Taiwan from 1996 to 2003. Int J Gerontol 2013;7:97-101.

3. Wada $\mathrm{T}$, Ishine $\mathrm{M}$, Sakagami $\mathrm{T}$, Kita $\mathrm{T}$, Okumiya $\mathrm{K}$, Mizuno $\mathrm{K}$, et al. Depression, activities of daily living, and quality of life of community-dwelling elderly in three Asian countries: Indonesia, Vietnam, and Japan. Arch Gerontol Geriatr 2005;41:271-280.

4. Wlodarczyk JH, Brodaty H, Hawthorne G. The relationship between quality of life, Mini-Mental State Examination, and the Instrumental Activities of Daily Living in patients with Alzheimer's disease. Arch Gerontol Geriatr 2004;39:25-33.

5. Elliott AF, McGwin G Jr, Owsley C. Health-related quality of life and visual and cognitive impairment among nursing-home residents. Br J Ophthalmol 2009;93:240-243.

6. Akdag B, Aslan Telci E, Cavlak U. Factors affecting cognitive function in older adults: a Turkish sample. Int $J$ Gerontol 2013;7:137-141.

7. Helvik AS, Skancke RH, Selbaek G. Screening for depression in elderly medical inpatients from rural area of Norway: prevalence and associated factors. Int J Geriatr Psychiatry 2010;25:150-159.

8. Helvik AS, Engedal K, Selbaek G. The quality of life and factors associated with it in the medically hospitalised elderly. Aging Ment Health 2010;14:861-869.

9. Demir Akca AS, Saraçlı Ö, Emre U, Atasoy N, Güdül S, Özen Barut B, et al. Relationship of cognitive functions with daily living activities, depression, anxiety and clinical variables in hospitalized elderly patients. [Turkish]. Arch Neuropsychiatr 2014;51:267-274.

10. Folstein MF, Folstein SE, McHugh PR. "Mini-mental state". A practical method for grading the cognitive state of patients for the clinician. J Psychiatr Res 1975;12:189-198.

11. Güngen C, Ertan T, Eker E, Yaşar R, Engin F. Reliability and validity of the standardized Mini Mental State Examination in the diagnosis of mild dementia in Turkish population. Turk Psikiyatri Derg 2002;13:273-281.

12. Burke WJ, Roccaforte WH, Wengel SP. The short form of the Geriatric Depression Scale: a comparison with the 30-item form. J Geriatr Psychiatry Neurol 1991;4:173-178.

13. Ertan T, Bugay G, Eker E. The reliability and validity of the short version of Geriatric Depression Scale in the old Turkish population: GDS-15, GDS-10, GDS-4. 5. In: Ulusal Geropsikiyatri Sempozyumu; June 10-12 2004; İstanbul, Turkey. [Turkish]

14. Beck AT, Epstein N, Brown G, Steer RA. An inventory for measuring clinical anxiety: psychometric properties. J Consult Clin Psychol 1988;56:893-897.

15. Ulusoy M, Şahin NH, Erkmen H. Turkish version of the Beck Anxiety Inventory: Psychometric properties. J Cogn Psychother 1998;12:163-172.

16. Power M, Quinn K, Schmidt S; WHOQOL-OLD Group. Development of the WHOQOL-old module. Qual Life Res 2005; 14:2197-2214.

17. Eser S, Saatli G, Eser E, Baydur H, Fidaner C. The reliability and validity of the Turkish Version of the World Health Organization Quality of Life Instrument-Older Adults Module (WHOQOL-Old). Turk Psikiyatri Derg 2010;21:37-48.

18. Özyurt BC, Eser E, Çoban G, Akdemir SN, Karaca İ, Karakoç Ö. The evaluation of influencing factors of "quality of life" in the elderly in Muradiye district, Manisa. Turkish $J$ Geriatr 2007;10:117-123.

19. Aydın S, Karaoğlu L. The Quality of life and the influencing factors among the population over 65 living in Gaziantep city center. Turkish J Geriatr 2012;15:424-433. 
20. Bowling A, Farquhar M, Grundy E. Associations with changes in life satisfaction among three samples of elderly people living at home. Int J Geriatr Psychiatry 1996;11: 1077-1087.

21. Tajvar M, Arab M, Montazeri A. Determinants of health-related quality of life in elderly in Tehran, Iran. BMC Public Health 2008;8:323.

22. Peel NM, Bartlett HP, Marshall AL. Measuring quality of life in older people: Reliability and validity of WHOQOL-OLD. Australas J Ageing 2007;26:162-167.

23. Diker J, Etiler N, Y1ldız M, Şeref B. Association between cognitive status and activities of daily living, life quality and some demographic variables in older than 65. Anatolian $J$ Psychiatry 2001;2:79-86.

24. Güngör Tavşanlı N, Öçelik H, Karadakovan A. Examine of quality of life of elderly indivudals suffering pain. Agri 2013;25:93-100.

25. Güler N, Akal Ç. Quality of life of elderly people aged 65 years and over living at home in Sivas, Turkey. Turkish J Geriatr 2009;12:181-189.

26. Tyrrell J, Paturel L, Cadec B, Capezzali E, Poussin G. Older patients undergoing dialysis treatment: cognitive functioning, depressive mood and health-related quality of life. Aging Ment Health 2005;9:374-379.

27. Arslantas D, Unsal A, Metintas S, Koc F, Arslantas A. Life quality and daily life activities of elderly people in rural areas, Eskişehir (Turkey). Arch Gerontol Geriatr 2009;48:127-131.

28. Kirmizioglu Y, Doğan O, Kuğu N, Akyüz G. Prevalence of anxiety disorders among elderly people. Int $J$ Geriatr Psychiatry 2009;24:1026-1033.

29. Barcelos-Ferreira R, Nakano EY, Steffens DC, Bottino CM. Quality of life and physical activity associated to lower prevalence of depression in community-dwelling elderly subjects from Sao Paulo. J Affect Disord 2013;150:616-622.

30. Li L, Chang HJ, Yeh HI, Hou CJ, Tsai CH, Tsai JP. Factors associated with leisure participation among the elderly living in long-term care facilities. Int J Gerontol 2010;4:69-74.

31. Xavier FM, Ferraz MP, Marc N, Escosteguy NU, Moriguchi EH. Elderly people's definition of quality of life. Rev Bras Psiquiatr 2003;25:31-39. 